\title{
Systemic and Coronary Hemodynamic Effects of $\beta$-Adrenoceptor Blocking Agents in Coronary Artery Disease
}

\author{
Yoshimasa YABE, M.D. and Takeshi Morishita, M.D.*
}

\section{Summary}

Systemic and coronary hemodynamic effects of acebutolol $(10 \mathrm{mg}$ i.v.), a cardioselective $\beta$-adrenoceptor blocking agent were investigated in 11 patients with coronary artery disease and significant arterial obstructive lesions. Efficacy was assessed by simultaneous left and right heart catheterization and with an inlaying Webster thermodilution catheter in the coronary sinus. The data were compared with data from 7 other patients who received $2 \mathrm{mg}$ i.v. of propranolol, a non-cardioselective $\beta$-blocker. With acebutolol, (1) the heart rate was reduced significantly $(p<0.01)$, (2) no significant changes were observed in the LVSP, LVEDP, mean PWP, LVmax dp/dt/p, LV negative $d p / d t / p, C I, S W I$ and SPI, (3) CSF and $\mathrm{MVO}_{2}$ decreased significantly $(\mathrm{p}<0.01) 5$ min after injection and (4) the CVR showed a significant elevation $(p<0.05)$ after $5 \mathrm{~min}$. With propranolol, ( 1$)$ the heart rate decreased significantly $(p<0.05)$, (2) there were no significant changes in LVSP and LVEDP, (3) the mean PWP increased significantly $(p<0.05)$, (4) the $L V \max d p / d t / p, C I$ and SWI decreased significantly $(\mathrm{p}<0.05)$, (5) the CSF and $\mathrm{MVO}_{2}$ decreased markedly $(p<0.01)$ and $(6)$ the GVR increased markedly $(p<0.01)$.

As compared to the effects of $2 \mathrm{mg}$ i.v. of propranolol, those produced by acebutolol ( $10 \mathrm{mg}$ i.v.) were characterized by a predominant negative chronotropic action with minimal negative inotropic action, combined with a reduction in CSF and $\mathrm{MVO}_{2}$. The findings suggest that the efficacy of acebutolol in pump failure caused by myocardial ischemia during effort angina is mediated by improvement of the myocardial oxygen demand-supply imbalance.

\section{Additional Indexing Words :}

Acebutolol Propranolol Stable effort angina Left ventricular performance Coronary circulation

TN 1969, Fitzgerald ${ }^{13}$ and Lands et al ${ }^{2)}$ reported that $\beta$-blockers possess (1) membrane-stabilizing activity, (2) intrinsic sympathomimetic ac-

\footnotetext{
From the Cardiovascular Diagnostic Laboratory Center, Toho University School of Medicine and the First Department of Internal Medicine,* Toho University School of Medicine, Tokyo, Japan. Address for reprint: Yoshimasa Yabe, M.D., Cardiovascular Diagnostic Laboratory Center, Toho University School of Medicine, 6-11-1, Omori-nishi, Ota-ku, Tokyo 143, Japan.

Received for publication April 9, 1984.

Manuscript revised July 17, 1987.
} 
tivity and (3) cardioselective actions upon $\beta$-adrenoceptors. Acebutolol was described in 1973 by Basil et al $^{3 \prime}$ to be a cardioselective $\beta$-blocking agent with only a minimal negative inotropic action. Thus, it was suggested for clinical application for such untoward reactions as bronchospasm and Raynaud's phenomenon.

A variety of substances with $\beta$-adrenoceptor blocking activity are currently in clinical use as drugs for treatment of ischemic heart diseases, arrhythmias and hypertension. Since the demonstration of antianginal effects of $\beta$-blockers, due to reduction of myocardial oxygen demand, their clinical application in the treatment of effort angina pectoris has become virtually universal. On the other hand, the adverse effects of $\beta$-blockers such as spasms of bronchial smooth muscles and potential enhancement of heart failure through their negative inotropic actions are also widely recognized.

The hemodynamic effects of propranolol have been studied extensively in humans, and the clinical use of acebutolol as a cardioselective $\beta$-blocker has received increased attention. However, reports of clinical studies concerning the hemodynamic effects of acebutolol are rare. ${ }^{4)-6)}$ The present study examined the effects of intravenously injected acebutolol on parameters reflecting systemic and coronary hemodynamics and myocardial energetics. These studics involved simultaneous left and right heart catheterization in patients with arteriographically established coronary arterial diseases.

\section{Methods}

Eighteen patients with coronary diseases hospitalized for cineangiographic examination at the Cardiovascular Diagnostic Laboratory Center, Toho University School of Medicine were subjects in this study. They ranged in age from 22 to 70 years, with a mean age of 50.1 years. Eleven patients were treated with acebutolol $(10 \mathrm{mg})$, and 7 patients with propranolol (2 mg). All patients were diagnosed as class II or III stable effort angina according to the Ganadian Heart Association Criteria (Tables I and II).

Acebutolol (10 mg) or propranolol $(2 \mathrm{mg}$ ) was dissolved in $20 \mathrm{ml}$ of physiological saline and injected slowly into the cephalic median vein over a 2 min period. Various hemodynamic parameters were recorded continuously from a preinjection baseline period until $10 \mathrm{~min}$ after injection. In every case, continuous, simultaneous recordings were made of the heart rate (HR), left ventricular systolic pressure (LVSP), left ventricular end-diastolic pressure (LVEDP), mean pulmonary wedge pressure (mean PWP), LV max $\mathrm{dp} / \mathrm{dt}, \mathrm{LV} \max \mathrm{dp} / \mathrm{dt} / \mathrm{p}$ and $\mathrm{LV}$ peak negative $\mathrm{dp} / \mathrm{dt}$ via left and right heart 
Table I. Clinical Features and Hemodynamics in Patients with Stable Effort Angina Pectoris (Acebutolol Group)

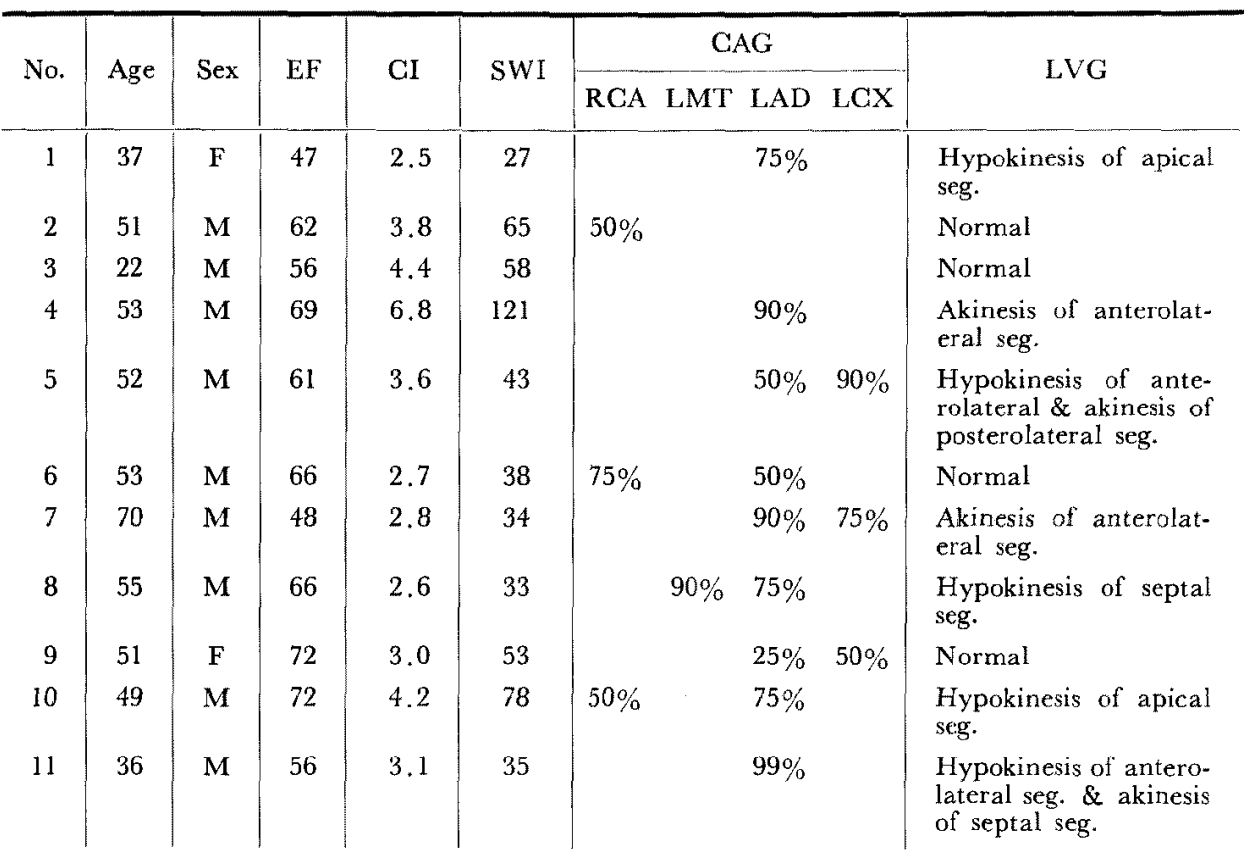

Abbreviations: $\quad \mathrm{EF}=$ ejection fraction; $\mathrm{CI}=$ cardiac index; $\mathrm{SWI}=$ stroke work index; $\mathrm{CAG}$ $=$ coronary arteriogram; $\mathbf{R C A}=$ right coronary artery; $\mathrm{LMT}=$ left main trunk; $\mathrm{LAD}=\mathrm{left}$ anterior descending artery; LCX =left circumflex artery; LVG=left ventriculogram.

Table II. Clinical Features and Hemodynamics in Patients with Stable Effort Angina Pectoris (Propranolol Group)

\begin{tabular}{c|c|c|c|c|c|ccc|l}
\hline No. & Age & Sex & EF & GI & SWI & \multicolumn{3}{|c|}{ CAG } & \multicolumn{1}{|l}{ LVG } \\
\hline 1 & 65 & M & 68 & 2.5 & 44 & & $75 \%$ & $50 \%$ & Normal \\
2 & 44 & M & 68 & 4.0 & 51 & $50 \%$ & $90 \%$ & $75 \%$ & Normal \\
3 & 49 & M & 69 & 3.6 & 67 & $99 \%$ & $90 \%$ & $75 \%$ & Normal \\
4 & 52 & M & 82 & 3.0 & 80 & & & & $\begin{array}{l}\text { Hyperkinesis, Myocardial } \\
\text { hypertrophy }\end{array}$ \\
5 & 55 & M & 62 & 3.3 & 25 & $99 \%$ & $90 \%$ & $75 \%$ & Hypokinesis 4, 6 (AHA seg.) \\
6 & 53 & $\mathrm{M}$ & 74 & 2.8 & 64 & $75 \%$ & $50 \%$ & $100 \%$ & Akinesis 4 (AHA seg.) \\
7 & 54 & $\mathrm{M}$ & - & 3.0 & 75 & & $90 \%$ & $25 \%$ & Normal
\end{tabular}

Abbreviations: see Table 1.

catheterization. The cardiac index (CI), stroke work index (SWI), stroke power index (SPI) and total peripheral vascular resistance (TPR) were determined before and $10 \mathrm{~min}$ after the injection of each drug for comparative assessments. An 8F Sones catheter was used for the left heart and a Swan- 
Ganz thermodilution catheter for the right heart. For evaluation of the coronary circulation, the coronary sinus blood flow was measured using a thermodilution catheter (CCU-7U-90B type, Webster) and a thermo-flow (810-302H, Goodman). The aortic and coronary sinus mean pressures were recorded simultaneously and blood was sampled serially for blood oxygen assays, to obtain data for assessments of coronary hemodynamics and myocardial metabolism.

The protocol for studying coronary hemodynamics consisted of measurements of the coronary sinus flow (CSF), coronary vascular resistance (CVR) and myocardial oxygen consumption $\left(\mathrm{MV}_{2}\right)$ in a control period [after an isometric handgrip (IHG) exercise test], at 5 and $10 \mathrm{~min}$ following an i.v. injection of the drug made after complete return to the control level, and following another IHG stress test. The IHG stress method") simultaneously measured grasping power with a bridge circuit (using smedray style, aluminium alloy-semiconductor strain gauge) and pressure with a transducer. The data were recorded with a Mingo-graph recorder. The optimum load volume was determined from the sustained work curve of $50 \%$ maximum voluntary contraction (MVG) following the initial maximum voluntary contraction, and was maintained for $2 \mathrm{~min}$. A Siemens catheter system and an AVD system were used for recording intracardiac pressure and cardiac function paramcters and for automated analysis of left ventricular geometry. A Philips Cardiodiagnost was used for cineangiography. Data were analyzed statistically by the Student's t-test (paired comparison) and expressed as mean \pm standard error (SE) in figures.

\section{Results}

1) Heart rate (HR)

The HR was reduced by intravenous injection of acebutolol in all 11 patients; it decreased from a preinjection level of $68.2 \pm 6.2$ beats $/ \mathrm{min}$ to $64 \pm 7.0$ beats/min during injection and further to $62.2 \pm 3.9$ beats $/ \mathrm{min}$ at 2 min after injection. The $H R$ remained lowered as measured at 5 and $10 \mathrm{~min}$ post injection, with values of $62.5 \pm 4.5$ and $62.2 \pm 3.6$ beats $/ \mathrm{min}$, respectively. The decreases observed during the injection and at 2, 5 and $10 \mathrm{~min}$ after the injection were statistically significant at $\mathrm{p}<0.01, \mathrm{p}<0.05$ and $\mathrm{p}<0.05$, respectively.

Patients tended to display a transient initial elevation of HR during intravenous injection of propranolol. The HR declined following the injection, and the decreases at 5 and $10 \mathrm{~min}(66.1 \pm 2.0$ and $66.9 \pm 1.5$ beats $/ \mathrm{min}$, respectively) after injection were significant $(\mathrm{p}<0.01$ and $\mathrm{p}<0.05$, respec- 


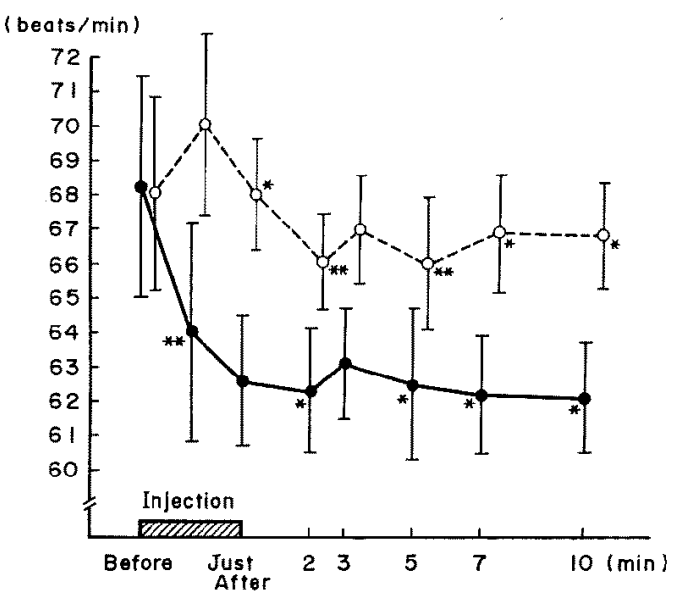

Fig. 1. Effect of acebutolol (O) and propranolol (O) on heart rate. Mean $\pm \mathrm{SE}, * \mathrm{p}<0.05, * * \mathrm{p}<0.01$.

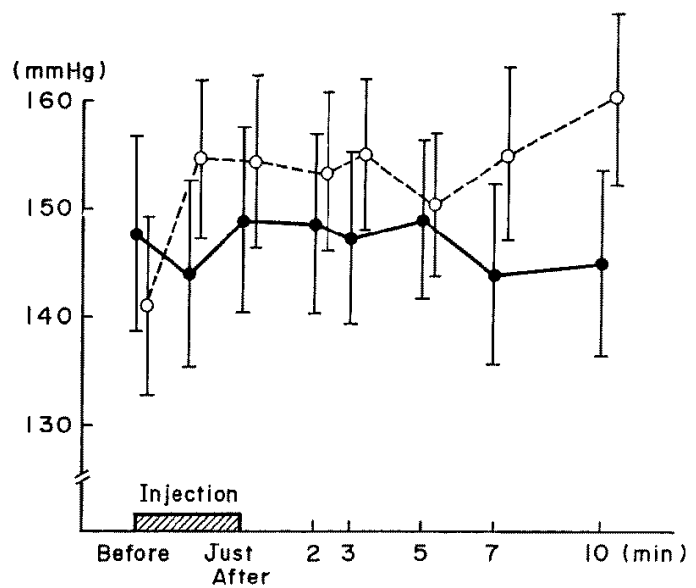

Fig. 2. Effect of acebutolol (O) and propranolol $(O)$ on left ventricular systolic pressure (LVSP). Mean \pm SE.

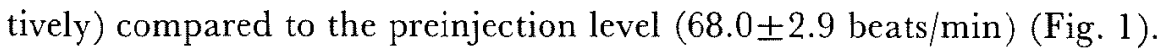

2) Left ventricular systolic pressure (LVSP)

This parameter tended to decline following injection of acebutolol but the difference was not statistically significant. There was a transitory initial elevation $(141.7 \pm 8.3 \mathrm{mmHg}$ to $154.5 \pm 7.0 \mathrm{mmHg}$ ) during the propranolol injections, but changes were not statistically significant at other times (Fig. 2).

3) Left ventricular end-diastolic pressure (LVEDP) and mean pulmonary wedge pressure (mean PWP)

The LVEDP did not change significantly in response to administration 


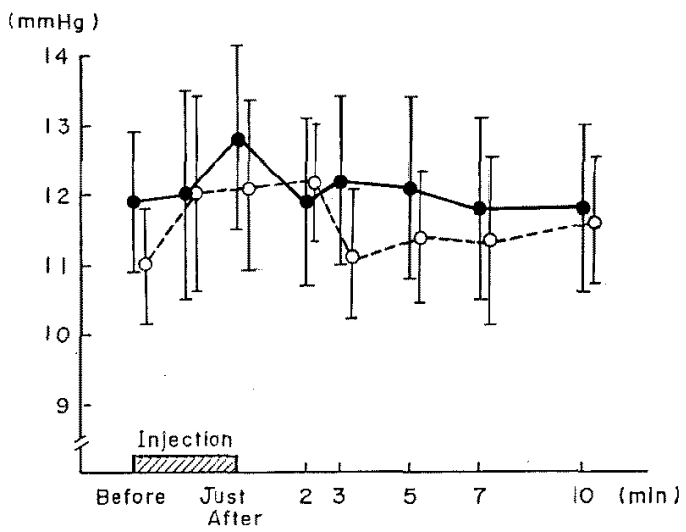

Fig. 3. Effect of acebutolol (O) and propranolol $(O)$ on left ventricular end-diastolic pressure (LVEDP). Mean \pm SE.

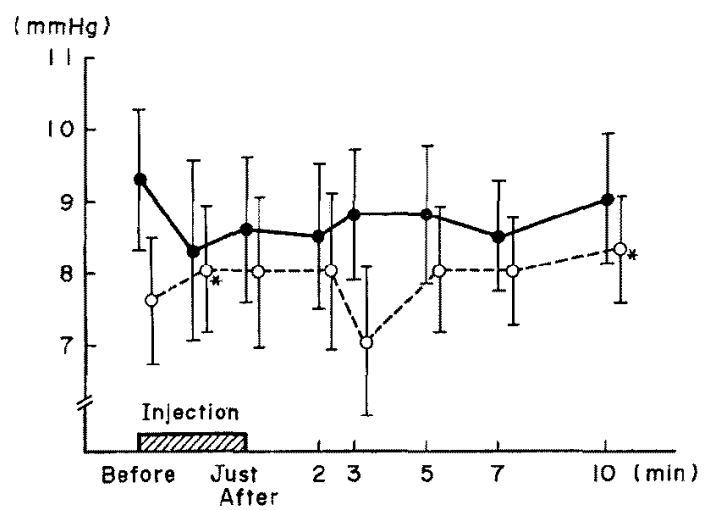

Fig. 4. Effect of acebutolol (O) and propranolol $(O)$ on mean pulmonary wedge pressure (mean $\mathrm{PWP}$ ). Mean $\pm \mathrm{SE},{ }^{*} \mathrm{p}<0.05$.

of either acebutolol or propranolol (Fig. 3). Although the mean PWP did not change significantly in response to acebutolol, it was elevated following administration of propranolol, with significant changes being observed during $(8.0 \pm 0.9 \mathrm{mmHg})$ and $10 \mathrm{~min}(8.3 \pm 0.8 \mathrm{mmHg})$ after the injection $(\mathrm{p}<$ 0.05 ) (Fig. 4).

4) $L V \max d p / d t / p$ and $L V$ negative $d p / d t / p$

The LVmax $d p / d t / p$ decreased slightly upon completion of the acebutolol injection $\left(46 \pm 1.0 \mathrm{~S}^{-1}\right.$ as against a preinjection value of $\left.48 \pm 1.1 \mathrm{~S}^{-1}\right)$ and returned virtually to the initial level after injection, i.e. $48 \pm 1.2 \mathrm{~S}^{-1}$, $47 \pm 1.0 \mathrm{~S}^{-1}$ and $47 \pm 0.9 \mathrm{~S}^{-1}$ at 2,5 and $7 \mathrm{~min}$, respectively. The change did not reach statistical significance. Propranolol produced a different response pattern. The LVmax dp/dt/p began to fall as injection was started from $60 \pm 2.85$ to $56 \pm 3.15$, and remained significantly lower during $\left(55.8 \pm 3.1 \mathrm{~S}^{-1}\right)$ 


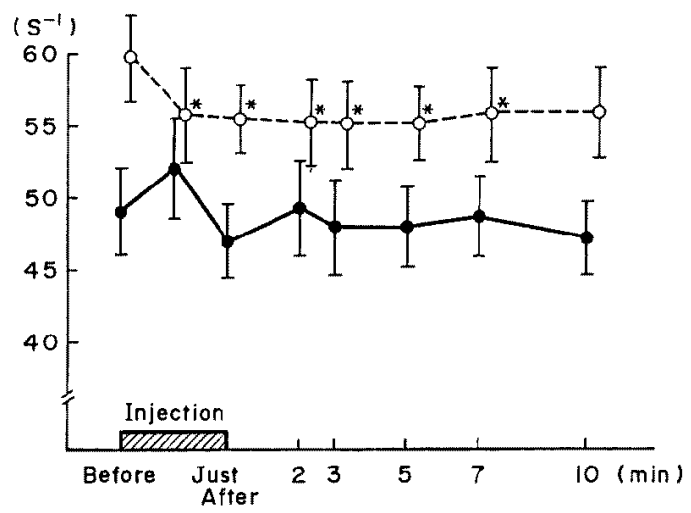

Fig. 5. Effect of acebutolol (O) and propranolol (O) on LVmax dp/ $\mathrm{dt} / \mathrm{p} . \quad$ Mean $\pm \mathrm{SE}, * \mathrm{p}<0.05$.

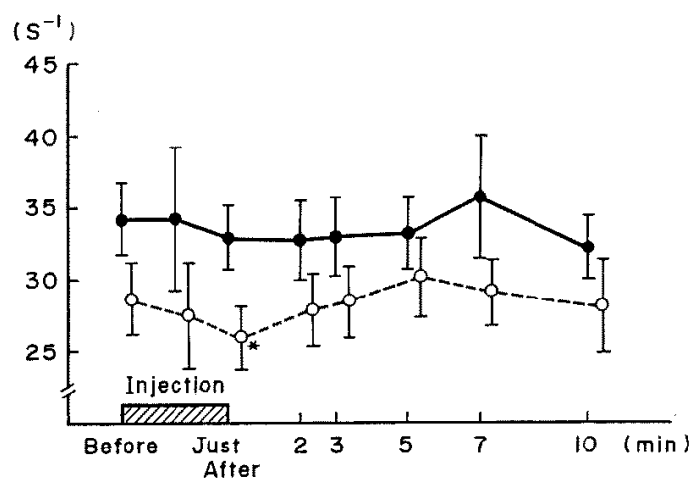

Fig. 6. Effect of acebutolol (O) and propranolol $(O)$ on negative dp/ $\mathrm{dt} / \mathrm{p} . \quad$ Mean $\pm \mathrm{SE},{ }^{*} \mathrm{p}<0.05$.

and $7 \mathrm{~min}\left(55.9 \pm 3.1 \mathrm{~S}^{-1}\right)$ after the injection $(\mathrm{p}<0.05)$ (Fig. 5). LV negative $\mathrm{dp} / \mathrm{dt} / \mathrm{p}$ was not affected by acebutolol injections; however, it decreased significantly after propranolol injections $(p<0.05)$ (Fig. 6).

5) Cardiac index (CI)

The CI was not affected significantly by intravenous injections of acebutolol. However, a significant drop in the CI was noted $10 \mathrm{~min}$ after intravenous injection of propranolol $2.2 \pm 0.5 \mathrm{~L} / \mathrm{min} / \mathrm{m}^{2}(\mathrm{p}<0.05)$, compared to an initial value of $3.15 \pm 0.2 \mathrm{~L} / \mathrm{min} / \mathrm{m}^{2}$ (Fig. 7).

6) LV stroke work index (SWI) and LV stroke power index (SPI)

The SWI did not change significantly after acebutolol injections. However, a significant decrease was observed $10 \mathrm{~min}$ after propranolol injections, $49.8 \pm 15 \mathrm{gm} / \mathrm{m}^{2}(\mathrm{p}<0.05)$, compared to an initial value of $69.5 \pm 10 \mathrm{gm} / \mathrm{m}^{2}$ (Fig. 7). By contrast, the SPI was not affected significantly by either propranolol or acebutolol administration, 

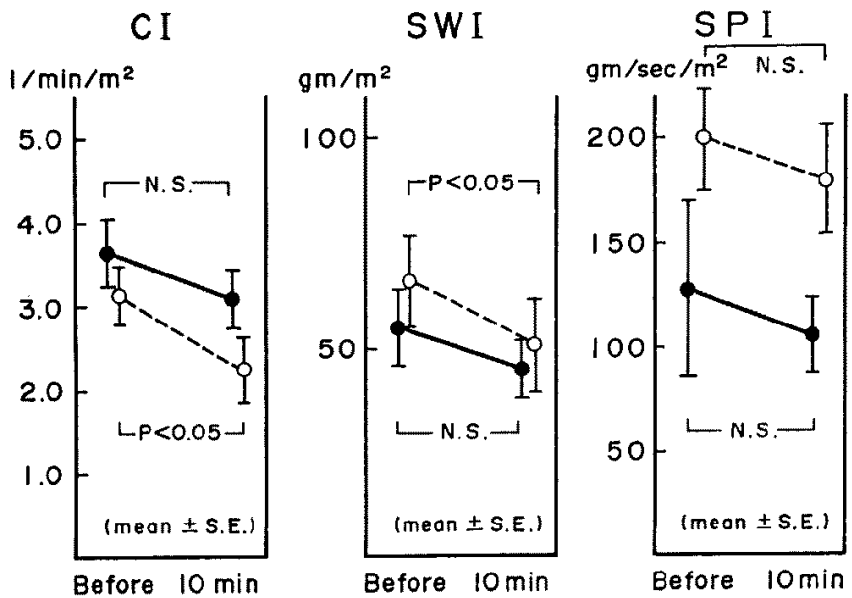

Fig. 7. Effect of acebutolol $(O)$ and propranolol $(O)$ on cardiac index (CI), stroke work index (SWI) and stroke power index (SPI).

\section{7) Coronary sinus blood flow (CSF)}

The control CSF value was $141.8 \pm 34.9 \mathrm{ml}$. It increased to $169.7 \pm$ $24.7 \mathrm{ml}$ immediately after the isometric handgrip exercise test (IHG stress test); the rate of its change was $+19.7 \%$. It was reduced significantly by intravenous injection of acebutolol, with values of $122.5 \pm 33.5(\mathrm{p}<0.01)$ and $118.8 \pm 33.2 \mathrm{ml}(\mathrm{p}<0.05)$ at 5 and $10 \mathrm{~min}$, respectively. An IHG stress test at $10 \mathrm{~min}$ after injection did not result in a significant difference from control or baseline acebutolol values $(121.8 \pm 34.1 \mathrm{ml})$.

Propranolol produced a marked fall in CSF, with values of $102 \pm 8.5$ $(\mathrm{p}<0.01)$ and $99 \pm 2.1 \mathrm{ml}(\mathrm{p}<0.01)$ at 3 and $5 \mathrm{~min}$, respectively, versus a control level of $135 \pm 21.9 \mathrm{ml}$. No appreciable increase in CSF occurred on subsequent IHG stress tests.

8) Coronary vascular resistance (CVR)

The CVR was not significantly affected by the IHG stress test $(924 \pm$ $125.0 \mathrm{mmHg} / \mathrm{ml} / \mathrm{min}$ versus control value of $975.0 \pm 293.9 \mathrm{mmHg} / \mathrm{ml} / \mathrm{min}$ ). Following intravenous acebutolol injections, the CVR increased significantly to $1163.7 \pm 422.5 \mathrm{mmHg} / \mathrm{ml} / \mathrm{min} \quad(\mathrm{p}<0.05)$ at $5 \mathrm{~min}$ and $1168.7 \pm 419.5$ $\mathrm{mmHg} / \mathrm{ml} / \mathrm{min}(\mathrm{p}<0.05)$ at $10 \mathrm{~min}$. The increase was sustained even after an IHG stress test.

Significant increases in CVR were observed following administration of propranolol, with values of $1118 \pm 43 \mathrm{mmHg} / \mathrm{ml} / \mathrm{min}(\mathrm{p}<0.01)$ at $3 \mathrm{~min}$ and $1076 \pm 16 \mathrm{mmHg} / \mathrm{ml} / \mathrm{min}(\mathrm{p}<0.01)$ at $5 \mathrm{~min}$ as against a control level of $900 \pm 318 \mathrm{mmHg} / \mathrm{ml} / \mathrm{min}$. However, these values did not differ significantly from values after acebutolol administration (at $5 \mathrm{~min}$ ). The elevation was sustained even after an isometric exercise test. 


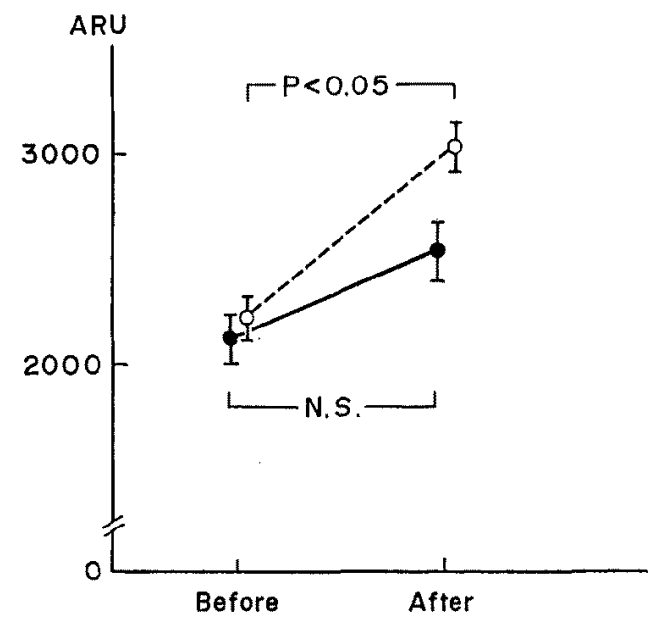

Fig. 8. Effect of acebutolol (O) and propranolol $(O)$ on total peripheral vascular resistance (TPR). Mean $\pm \mathrm{SE}, \mathrm{ARU}=$ absolute resistance unit (dyne $\left.\sec \mathrm{cm}^{-5} / \mathrm{m}^{2}\right)$. Total Vascular Resistance $=($ mean AP-LVEDP $) / \mathrm{CI}$.

\section{9) Myocardial oxygen consumption $\left(\mathrm{MVO}_{2}\right)$}

The $\mathrm{MVO}_{2}$ did not change significantly $(15.9 \pm 3.20 \mathrm{mmol} / \mathrm{ml})$ during IHG stress testing (compared to a control value of $15.09 \pm 2.85 \mathrm{mmol} / \mathrm{ml}$ ). It was significantly reduced by acebutolol, with values of $12.84 \pm 2.69(\mathrm{p}<$ $0.05)$ and $13.02 \pm 3.01 \mathrm{mmol} / \mathrm{ml}(\mathrm{p}<0.05)$ at 5 and $10 \mathrm{~min}$, respectively. The decrease persisted during subsequent IHG exercise testing.

This parameter also decreased after administration of propranolol, viz. $12.0 \pm 1.8(\mathrm{p}<0.02)$ and $11.4 \pm 0.9 \mathrm{mmol} / \mathrm{ml}(\mathrm{p}<0.02)$ at 3 and $5 \mathrm{~min}$, respectively (versus a control value of $15.3 \pm 6.4 \mathrm{mmol} / \mathrm{ml}$ ). It remained lowered even during subsequent IHG stress testing.

10) Total peripheral vascular resistance (TPR)

The TPR was not affected significantly by administration of acebutolol $\left(2500 \pm 150\right.$ dyne sec $\mathrm{cm}^{-5} / \mathrm{m}^{2}$ at $10 \mathrm{~min}$ as against a preinjection level of 2120 \pm 200 dyne $\sec \mathrm{cm}^{-5} / \mathrm{m}^{2}$ ). After propranolol administration, the TPR increased significantly to $3020 \pm 180$ dyne $\operatorname{sec~} \mathrm{cm}^{-5} / \mathrm{m}^{2}(\mathrm{p}<0.05)$ at $10 \mathrm{~min}$ from an initial value of $2220 \pm 200$ dyne $\mathrm{sec} \mathrm{cm}^{-5} / \mathrm{m}^{2}$ (Fig. 8).

\section{Discussion}

1) Hemodynamic effects

Acebutolol produced a profound negative chronotropic action at the usual therapeutic dose levels; the heart rate was reduced markedly $(\mathrm{p}<0.01)$ during and following injection. The anti-arrhythmic effects of acebutolol 
have been attributed to a membrane-stabilizing activity (quinidine-like activity), in addition to $\beta$-blocking activity. Sada et al ${ }^{8)}$ demonstrated noticeable quinidine-like activity of acebutolol at an optimal dose. It follows that a possible involvement of such nonspecific activity may constitute a factor in the significant negative chronotropic action of this drug.

Prichard and Gillam ${ }^{9}$ ascribed the antihypertensive effects of $\beta$-blockers to (1) stimulation of the autoregulatory system of blood vessels, (2) the inhibition of renin release and (3) the blockade of CNS $\beta$-receptors. In the present study, acebutolol or propranolol did not significantly affect either blood pressure, the left ventricular systolic pressure, or the left ventricular end-diastolic pressure (LVEDP).

Unlike propranolol, acebutolol did not seem to affect myocardial contractility. The $L V \max \mathrm{dp} / \mathrm{dt} / \mathrm{p}$, which is generally believed to be the most reliable measure of myocardial contractility, did not change significantly following an i.v. injection of $10 \mathrm{mg}$ acebutolol. On the other hand, a significant decrease of $L V \max d p / d t / p(p<0.05)$ was evident after propranolol injection. Since Hall et $\mathrm{al}^{10}$ reported also that intravenous administration of a higher dose $(60 \mathrm{mg})$ of acebutolol significantly reduced both heart rate and arterial pressure $(\mathrm{p}<0.05)$, increased the left ventricular end-diastolic pressure, and did not alter peak shortening and lengthening rates, the data suggest that an optimal dosage of acebutolol can be used without apprehension of suppressing myocardial contractility. By contrast, propranolol has a direct negative inotropic action and decreases pump failure.

The cardiac index and LV stroke work index or LV stroke power index were not significantly affected by acebutolol administration. This suggests the utility of acebutolol in effort angina pectoris, even in cases where the condition is complicated by pump failure due to excessive myocardial ischemia. Furthermore, unlike propranolol, acebutolol did not affect the total peripheral vascular resistance. Thus, acebutolol does not seem to exert a $\beta_{2}$-blocking effect at usual dose levels (i.e., $10 \mathrm{mg}$ which is equivalent therapeutically to $10 \mathrm{mg}$ propranolol ${ }^{11)}$ ).

2) Effects on the coronary hemodynamics

The ischemic heart disease in which a $\beta$-blocker is prescribed as the drug of first choice is effort angina pectoris. Factors determining myocardial oxygen consumption $\left(\mathrm{MVO}_{2}\right)$ include the heart rate, myocardial contractility, aortic pressure, and left ventricular wall stress. It is generally thought that $\beta$-blockers reduce myocardial oxygen consumption via inhibitory effects on these factors, including blockade of the $\beta$-stimulatory action of endogenous catecholamines. In the present study, myocardial oxygen consumption determined from the coronary arteriovenous oxygen content difference and 
coronary sinus blood flow showed a significant decrease $(\mathrm{p}<0.05)$ at $5-10$ min after intravenous injection of acebutolol. The significant decrease of myocardial oxygen consumption caused by acebutolol continued even during isometric exercise stress testing. This indicates the efficacy of acebutolol for effort angina arising from an imbalance between myocardial demands and oxygen supply through the coronary arteries.

Acebutolol affected the coronary blood flow but not the coronary vascular resistance in this study. The coronary sinus flow (CSF) $(141.8 \pm 34.9$ $\mathrm{ml}$ during the control period and $169.7 \pm 24.7 \mathrm{ml}$ during isometric exercise stress testing) was significantly reduced 5 and $10 \mathrm{~min}$ after intravenous injection of the drug, with significant differences being observed $(p<0.01$ and $\mathrm{p}<0.05$, respectively). By contrast, the coronary vascular resistance (CVR) was not affected significantly by the injection of acebutolol. The $\beta_{1}$-blocker properties of acebutolol, which produce a mild inhibition of myocardial contraction and a reduction in heart rate with consequent decrease in myocardial oxygen consumption, seem to be reflected in the reduction of coronary blood flow. It has been reported by Yasue ct al ${ }^{12)}$ that $\alpha$-adrenoceptors of coronary arteries assume control of large coronary vessels, thereby serving as a factor to evoke coronary artery spasms. Mekata et a ${ }^{13)}$ suggested that $\beta$ adrenoceptors act predominantly in the coronary arterioles to take part in the relaxation of coronary vessels. It follows then, that inhibition of the coronary arteriolar $\beta$-receptors by administration of acebutolol should lead to an increase in coronary vascular resistance. Furthermore, constriction of major coronary arteries by the predominance of $\alpha$-receptors may give rise to a decrease in coronary sinus blood flow. In response to propranolol injection, though, the coronary sinus blood flow was markedly reduced $(\mathrm{p}<0.01)$ and the coronary vascular resistance significantly enhanced $(\mathrm{p}<0.01)$ at both 3 and $5 \mathrm{~min}$ after injection. A coronary autoregulatory reaction was not observed on an isometric exercise test performed following the injection of propranolol. These findings suggest that higher doses of acebutolol may block $\beta_{2}$-adrenoceptors, with the eventual loss of cardioselective properties.

When administered at a usual dose level, acebutolol does not affect coronary vascular resistance. Furthermore, even if the coronary flow decreases, the tendency to contraction evoked by the drug in normal regions of coronary arteries may increase blood flow in ischemic lesions. Thus, the significant reduction in myocardial oxygen consumption after acebutolol injection provides strong evidence for its effectiveness in effort angina pectoris. 


\section{REFERENCES}

1. Fitzgerald JD: Perspectives in adrenergic beta-receptor blockade. Clin Pharmacol Ther 10: 292,1969

2. Lands AM, Arnold A, Mcauliff JP, Lunduena FP, Brown JG: Differentiation of receptor systems activated by sympathomimetic amines. Nature 214: 597, 1967

3. Basil B, Jordan R, Loveless AH, Maxwell DR: A comparison of the experimental antiarrhythmic properties of acebutolol and practolol. Br J Pharmacol 50: 323, 1974

4. Yabe Y, Hamano S, Koyama N, Ohsawa H, Uchi T, Morishita T: Effect of acebutolol on hemodynamics and cononary circulation in patients with coronary artery disease. Jpn Circ J 46 (suppl III): 588, 1982

5. Lee G, Joye JA, Mason DT, Jameson LA, Low R, Demaria AN: Comparative haemodynamic effects of intravenous acebutolol and propranolol (abstr), Beta-blockade in clinical practice: current trends. Proceedings of satellite symposium-held on the occasion of the VIII World Congress of Cardiology, Tokyo, p 72, 1978

6. Gotsman MS: The cardiac haemodynamics of acebutolol. Clin Trials J 11 (suppl III): 36, 1974

7. Hamano S, Yabe $\mathrm{Y}$, Koyama N, Ohsawa H, Uchi T: Effect of isometric exercise stress test on LV geometry, coronary hemodynamics. J Jap Coll Angiol 22: 703, 1982

8. Sada H, Ban T, Kojima M, Harada S: Membrane-stabilizing actions of acebutolol. Heart 13: 267, 1981 (in Japanese)

9. Prichard BNC, Gillam PMS: Use of propranolol (Inderal) in treatment of hypertension. Br Med J 2: 725, 1964

10. Hall RJC, Doran J, Pusey C, Mchaffie D, Gibson DG: The effect of nitroglycerin, betablockade with acebutolol and isometric stress on incoordinate left ventricular function. Eur Heart J 3: 23, 1982

11. Marmo E, Spaziante G, Pentimalli D, Marfella A, Ruggiero E, De Carlo R, Ruta A, Matera GM: Specific and non-specific activities of acebutolol, atenolol, metoprolol and propranolol: Comparative experimental studies. Intern J Clin Pharm Res 11: 41, 1982

12. Yasue H: Pathophysiology and treatment of coronary arterial spasm. Chest 78 (suppl): 216,1980

13. Mekata $\mathrm{H}$, Niu $\mathrm{H}$ : Electrical and mechanical responses of coronary artery smooth muscle to catecholamines. Jap J Physiol 19: 599, 1969 